\title{
Evaluation of Anthocyanin Profile and Color in Sweet Cherry Wine: Effect of Sinapic Acid and Grape Tannins during Aging
}

\author{
Mingyue Li ${ }^{1}$, Xinjie Zhao ${ }^{1}$, Yuxia Sun ${ }^{2}$, Zhen Yang ${ }^{1}$, Guomin Han ${ }^{1}$ and Xue Yang ${ }^{1, *}$ \\ 1 Shandong Provincial Key Laboratory of Microbial Engineering, School of Biologic Engineering, \\ Qilu University of Technology (Shandong Academy of Sciences), Jinan 250300, China; \\ 1043118297@stu.qlu.edu.cn (M.L.); zhaoxinjie1177@163.com (X.Z.); gina35@126.com (Z.Y.); \\ hanguomin@nwsuaf.edu.cn (G.H.) \\ 2 Institue of Agro-Food Science and Technology, Shandong Academy of Agricultural Sciences, \\ Jinan 250100, China; sunyuxia1230@163.com \\ * Correspondence: yangxue@qlu.edu.cn; Tel.: +86-186-5317-5734
}

Citation: Li, M.; Zhao, X.; Sun, Y.; Yang, Z.; Han, G.; Yang, X. Evaluation of Anthocyanin Profile and Color in Sweet Cherry Wine: Effect of Sinapic Acid and Grape Tannins during Aging. Molecules 2021, 26, 2923. https://doi.org/10.3390/ molecules 26102923

Academic Editor: Emanuele Boselli

Received: 12 April 2021

Accepted: 11 May 2021

Published: 14 May 2021

Publisher's Note: MDPI stays neutral with regard to jurisdictional claims in published maps and institutional affiliations.

Copyright: (C) 2021 by the authors Licensee MDPI, Basel, Switzerland. This article is an open access article distributed under the terms and conditions of the Creative Commons Attribution (CC BY) license (https:// creativecommons.org/licenses/by/ $4.0 /)$.

\begin{abstract}
Cherries are rich in bioactive phenolic compounds and are often fermented into cherry wines. The degradation of anthocyanins during storage will cause color deterioration. The study aimed to utilize sinapic acid and grape tannins in cherry wine to maintain a high fraction in the colored forms of anthocyanins, in order to maximize the color intensity, the latter being associated with good product quality. The effects on the anthocyanin profile and on color parameters of copigments, utilizing spectral measurement combined with UPLC-MS quantitative analysis, have been evaluated in sweet cherry wines. The copigmentation effect of sinapic acid and grape tannin was accompanied by the bathochromic shift and the hyperchromic effect, which lead to an increase in color intensity (lower $\mathrm{L}^{*}$, higher $\mathrm{a}^{*}$ and $\mathrm{b}^{*}$ ). During the aging process, sinapic and grape tannin increased the content of pyranoanthocyanins in cherry wine, especially the addition of sinapic acid makes the cherry wine generate 10-syringyl-pyranocyanidin-3-rutinoside. These results demonstrate that sinapic acid is suitable for adding before alcohol fermentation, while grape tannins can be added before aging.
\end{abstract}

Keywords: sweet cherry wine; sinapic acid; grape tannin; UPLC-Q/TOF-MS; anthocyanin analysis; color evaluation

\section{Introduction}

Sweet cherry (Prunus avium L.) is one of the fruits with high commercial value because of its rich nutrients and bioactive compounds with additional health benefits [1]. The main anthocyanins identified in sweet cherries are cyanidin-3-rutinoside and cyanidin-3glucoside, followed by peonidin-3-rutinoside and pelargonidin-3-glucoside [2,3]. Sweet cherries are also rich in phenolic acids, including neochlorogenic acid, chlorogenic acid and coumaric acid [2,4]. Ferulic acid and caffeic acid are also present in cherry fruits [5,6]. Cherries, like grapes, can be used in winemaking. Color is one of the important indicators of cherry wine, which determines its appeal to consumers. The color of cherry wine is affected by the type and concentration of anthocyanins [7]. However, anthocyanins are unstable and are affected by factors such as $\mathrm{pH}$, temperature, light, metal ions, enzymes, oxygen and the copigmentation effect $[8,9]$.

Copigmentation is widely used to improve and stabilize wine color, which shows hyperchromic effect, accompanied by bathochromic shift $[10,11]$. The interaction between anthocyanin and copigment forms a "sandwich" structure complex, which protects anthocyanins from nucleophilic attack [12]. Blanco-Vega et al. [13] monitored the formation of vitisin-like pyranoanthocyanin and hydroxyphenyl-pyranoanthocyanin in model wine by HPLC-DAD-ESI-MS/MS, using wine fermentation metabolites and hydroxycinnamic acids. Hydroxyphenyl-pyranoanthocyanins and vitisins are important anthocyanin-derived pigments in the wine aging process [14]. They have a higher color intensity and stability in a 
wider $\mathrm{pH}$ range compared with their anthocyanin precursors, which can be explained by the protective effect of the new pyran ring against the nucleophilic attack of water, which hinders the formation of the carbinol base $[15,16]$. They exist in the form of pyranoflavylium cations in wine, giving the wine color with an orange hue [17,18]. Sun et al. [19] reported that pyranoanthocyanins synthesized by the reaction of malvidin-3-O-glucoside with acetone, pyruvate, ferulic acid, caffeic acid and sinapic acid are more efficiently resistant to bleaching by $\mathrm{SO}_{2}$. Among them, vitisin A shows the strongest resistance.

Flavan-3-ols, hydroxycinnamic acid and flavonols are considered to be the main copigments in wine [20]. Yawadio and Morita [21] added carboxylic acid to the anthocyanin-rich fraction of black rice, which can enhance the color of the juice during storage and has the highest efficiency for sinapic acid. Ko et al. [22] added sinapic acid to the anthocyanin solution of black soybean and stored at room temperature for $36 \mathrm{~h}$, the remaining anthocyanin content increased significantly with the concentration of sinapic acid. Compared with the disubstituted (caffeic acid and ferulic acid) and the monosubstituted one (p-coumaric acid), the reaction kinetics of the trisubstituted (sinapic acid) hydroxycinnamic acid toward malvidin-3-glucoside has moderate enhancement [13]. Tannins are often added to improve aroma, taste and long-term color stability [23] in grape winemaking. Liu et al. [24] studied the effects of adding five kinds of tannins to the "Cabernet Sauvignon wine" on anthocyanins and color characteristics. The results showed that grape seed tannins were more effective in enhancing the color intensity of wine. Grape tannins are called condensed tannins and are composed of flavan-3-ol subunits, including catechins, epicatechins, epicatechin-gallate and epigallocatechin [25].

In this study, sinapic acid and grape tannin (factor 1) were added to sweet cherry juice before and after alcohol fermentation (factor 2), respectively, during the wine-making process. Then, the color, the composition profile and content of anthocyanin of cherry wine during the 12-month aging stage were investigated. The study aimed to utilize sinapic acid and grape tannins in cherry wine to maintain a high fraction in the colored forms of anthocyanins, in order to maximize the color intensity, the latter being associated with good product quality.

\section{Materials and Methods}

\subsection{Materials and Chemicals}

Cherry juice were made from sweet cherry of "Tieton" grown in Liaocheng, Shangdong Province (China). The soluble solid content of initial cherry juice was 20 Brix, and its $\mathrm{pH}$ was 3 .

Sinapic acid was purchased from Shanghai Yuanye Bio-Technology Co., Ltd. (Shanghai, China). Grape tannin (TRS-V) was purchased from Shanghai Jatou industrial and commercial Co., Ltd. (Shanghai, China). Cyanidin-3-glucoside chloride (purity $>98 \%$, HPLC) was obtained from Meilun Biotechnology Co. (Dalian, China). LC-MS grade acetonitrile was purchased from Merck (Darmstadt, Germany). LC-MS grade formic acid was purchased from Honeywell Fluka (Seelze, Germany). Ultrapure water was prepared by the Millipore Direct-Q 8 UV-R ultrapure water system (Sigma-Aldrich, St. Louis, MO, USA).

\subsection{Cherry Wines}

Fresh cherry juice was packed in 15 fermentation tanks of $2.5 \mathrm{~L}$ capacity, divided into 5 groups of different treatments. Each group was processed in triplicate. The details of the five groups were as follows:

- CK: normal winemaking, no copigment added.

- BFSA: $300 \mathrm{mg} / \mathrm{L}$ sinapic acid added before alcohol fermentation.

- AFSA: $300 \mathrm{mg} / \mathrm{L}$ sinapic acid added after alcohol fermentation.

- BFGT: $300 \mathrm{mg} / \mathrm{L}$ grape tannins added before alcohol fermentation.

- AFGT: $300 \mathrm{mg} / \mathrm{L}$ grape tannins added after alcohol fermentation.

(CK: control group; BF: before alcohol fermentation; AF: after alcohol fermentation; SA: sinapic acid; GT: grape tannin). 
About $0.3 \mathrm{~g} / \mathrm{L}$ of active dry yeasts EC1118 (Lalvin Co., Fredericia, Denmark) were activated and mixed in each container. The alcoholic fermentation was then allowed at $25^{\circ} \mathrm{C}$ for 11 days. After fermentation, the solids were removed, and each group was bottled with $\mathrm{SO}_{2}$ at $40 \mathrm{mg} / \mathrm{L}$ and aged for 12 months at $10^{\circ} \mathrm{C}$. Cherry wine samples were taken in the 0th, 3rd, 6th and 12th months after bottle aging, respectively, and the samples were stored at $-80^{\circ} \mathrm{C}$ for UPLC-MS analysis.

\subsection{Total Monomeric Anthocyanins and Polymeric Color}

According to the method of Giusti et al. [26] with some modifications, the content of total monomeric anthocyanins (TAs) was determined by the $\mathrm{pH}$-differential method, and the polymeric color was determined by the bisulfite bleaching method.

The total monomeric anthocyanins were calculated as follows:

Total monomeric anthocyanins $(\mathrm{mg} / \mathrm{L})=\mathrm{A} \times \mathrm{DF} \times \mathrm{MW} \times 1000 /(\varepsilon \times 1)$

$$
\mathrm{A}=\left(\mathrm{A}_{520 \mathrm{~nm}}-\mathrm{A}_{700 \mathrm{~nm}}\right)_{\mathrm{pH} 1.0}-\left(\mathrm{A}_{520 \mathrm{~nm}}-\mathrm{A}_{700 \mathrm{~nm}}\right)_{\mathrm{pH} 4.5}
$$

where MW is the molecular weight of cyanidin-3-glucoside, $\varepsilon$ is the molar absorptivity of cyanidin-3-glucoside and DF is the dilution factor.

The polymeric color was determined as follows:

$$
\text { Polymeric color }=\left[\left(\mathrm{A}_{420 \mathrm{~nm}}-\mathrm{A}_{700 \mathrm{~nm}}\right)+\left(\mathrm{A}_{520 \mathrm{~nm}}-\mathrm{A}_{700 \mathrm{~nm}}\right)\right]_{\mathrm{SO} 2} \times \mathrm{DF}
$$

where $\mathrm{A}$ is the absorbance of the bisulfite-treated sample

\subsection{Determination of the Copigmentation Effect}

The cherry wine was diluted 10 times using a potassium chloride buffer, $\mathrm{pH}$ 1.0. The $\lambda_{\max }$ and $A_{\max }$ were obtained by scanning the 400 to $700 \mathrm{~nm}$ wavelength range $(\Delta \lambda=1 \mathrm{~nm})$, with a microplate reader (BioTek Instruments, Inc. Winooski, VT, USA).

The copigmentation (M) value, which indicates the copigmentation effect, was obtained using the following formula [27]:

$$
\mathrm{M}=\left[\left(\mathrm{A}-\mathrm{A}_{0}\right) / \mathrm{A}_{0}\right] \times 100 \%
$$

where $\mathrm{A}$ and $\mathrm{A}_{0}$ are the absorbance value at $520 \mathrm{~nm}$ of the copigment-treated and control sample, respectively.

\subsection{Color Evaluation}

The absorbance values of undiluted cherry wine samples were measured at 420, 520 and $620 \mathrm{~nm}$, respectively [28].

$$
\text { Color intensity }(\mathrm{CI})=\mathrm{A}_{420}+\mathrm{A}_{520}+\mathrm{A}_{620} \text { Hue }(\mathrm{H})=\mathrm{A}_{420} / \mathrm{A}_{520} .
$$

The color parameters were measured using the CIELAB method. Absorption of undiluted cherry wine samples was measured at 450,520, 570 and $630 \mathrm{~nm}$, respectively. The $L^{*}, a^{*}$ and $b^{*}$ values were calculated using the formula reported by Han et al. [29].

\subsection{UPLC-MS Analysis of Cherry Wine Anthocyanins}

The detection and identification of anthocyanins in cherry wines were characterized by an ultraperformance liquid chromatography system (ACQUITY, H-Class, Waters Corporation, Milford, MA, USA) equipped with a time-of-flight mass spectrometer (Q-TOF-MS, Impact II, Bruker, Germany). Anthocyanin separation was performed using an Acquity BEH C18 column $(100 \times 2.1 \mathrm{~mm}$ i.d., $1.7 \mu \mathrm{m}$; Waters Corporation, Milford, MA, USA). All wine samples, which were filtered with $0.22 \mu \mathrm{m}$ NYLON66 filters, were injected into the column. The mobile phase consisted of $0.1 \%$ aqueous formic acid (A) and acetonitrile (B) with the following gradient elution: $0-5 \mathrm{~min}: 5 \% \mathrm{~B} ; 5-12 \mathrm{~min}: 5-20 \% \mathrm{~B} ; 12-20 \mathrm{~min}$ : $20-40 \%$ B; $20-20.1$ min: $40-100 \%$ B; $20.1-25$ min: $100 \%$ B; $25-25.1 \mathrm{~min}: 100-5 \%$ B; $25.1-30 \mathrm{~min}$ : 
$5 \% \mathrm{~B}$. The flow rate of the mobile phase was $0.45 \mathrm{~mL} / \mathrm{min}$, and the detection wavelength was $520 \mathrm{~nm}$. The ESI in positive ionization mode was used for the identification of anthocyanins. Mass spectrometry conditions were set as follows: end plate offset, $500 \mathrm{~V}$; capillary voltage, $3500 \mathrm{~V}$; nebulizer, $2.0 \mathrm{Bar}$; dry gas, $8.0 \mathrm{~L} / \mathrm{min}$; dry temperature, $220^{\circ} \mathrm{C}$; collision energy, $7.0 \mathrm{eV}$. The mass ranged from 100 to $1500 \mathrm{~m} / \mathrm{z}$. Anthocyanins were quantified as cyanidin-3-O-glucoside equivalents.

\subsection{Data Analysis}

Statistical analysis was carried out using one-way analysis of variance and Duncan's multiple range test to determine significant differences $(p<0.05)$ among the means by IBM SPSS statistics 26 (SPSS Inc., Chicago, IL, USA). The results are expressed as a mean \pm standard deviation. Multilinear regression (MLR) was analyzed by SPSS. The contents of eight anthocyanins and TAs were independent variables, and the four color parameters $\left(\lambda_{\max }\right.$, $\mathrm{A}_{\max }, \mathrm{CI}$ and $\mathrm{H}$ ) were dependent variables.

\section{Results}

\subsection{Effects of Copigments on Total Monomeric Anthocyanins in Cherry Wine}

Adding copigments is an effective way to enhance the stability of natural anthocyanins in a food system by the copigmentation effect $[8,30,31]$. The changes of total monomeric anthocyanins of cherry wine samples stored at $10{ }^{\circ} \mathrm{C}$ are shown in Figure 1A. The total monomeric anthocyanin content of the BFSA group in the aging stage was significantly higher than that of the control group, but the content of the AFSA, BAGT and AFGT groups was not significantly different from that of the control group. The degradation of anthocyanins is always accompanied by the formation of polymeric color, which is consistent with the research of Sinela et al. [32] and Jiang et al. [33]. After 3 months of aging, the copigment also had a significant effect on the polymeric color of cherry wine $(p<0.05)$ (Figure 1B). The increase of polymeric color may be caused by several factors, including condensation, copigmentation or anthocyanin degradation [34,35]. In other words, the increase in polymeric color during the aging process may be because the reaction between anthocyanins themselves or with other phenolic compounds is strengthened by adding copigments.

A

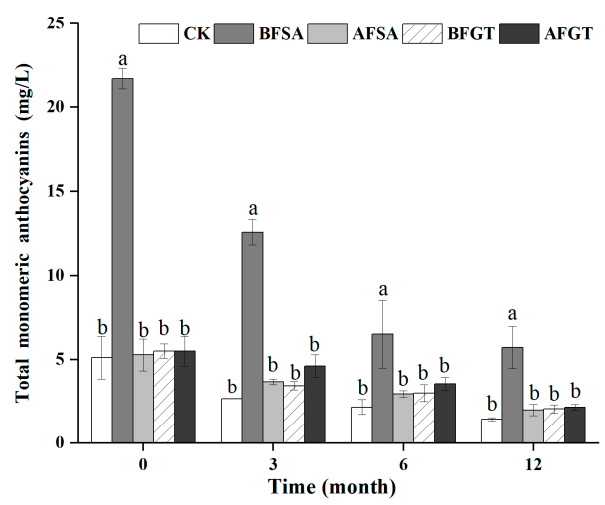

B

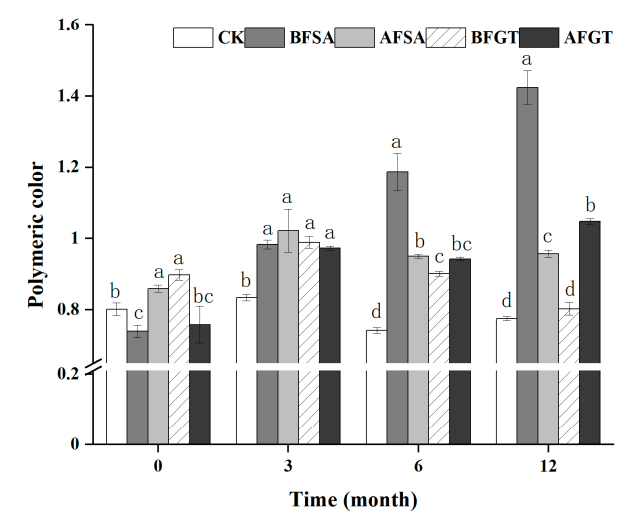

Figure 1. Effects of added sinapic acid and grape tannin on the total monomeric anthocyanins (A) and polymeric color (B) of cherry wine. Samples with different letters are significantly different $(p<0.05)$.

\subsection{Evaluation of the Copigmentation Effect of Copigments on Anthocyanins in Cherry Wine}

Table 1 shows the changes in the wavelength at maximum absorbance and the maximum absorbance $\left(\lambda_{\max }\right.$ and $\left.\mathrm{A}_{\max }\right)$ of cherry wines during one year of aging. Compared with the control, the BFSA group showed an ideal bathochromic shift $(5.3 \mathrm{~nm})$ at the beginning of aging. However, BFGT even had a hypsochromic shift of $2.7 \mathrm{~nm}$. After one year of aging, the copigment-treated group showed significant bathochromic shift 
$(p<0.05)$. Similarly, the four treatments had different degrees of hyperchromic effect. At the beginning of aging, the $A_{\max }$ value of BFSA increased by $96 \%$, while the hyperchromic effects of AFSA, BFGT and AFGT were not significantly different from those of the control group. During 3-12 months of aging, the $A_{\max }$ of the copigment-treated cherry wine was significantly higher than that of the control group, showing a favorable hyperchromic effect $(p<0.05)$.

Table 1. Effects of added sinapic acid and grape tannin on $\lambda_{\max }$ and $A_{\max }$ of cherry wine.

\begin{tabular}{|c|c|c|c|c|c|c|}
\hline Time (Month) & Index Tested & CK & BFSA & AFSA & BFGT & AFGT \\
\hline \multirow[t]{2}{*}{0} & $\lambda_{\max }$ & $506.67 \pm 1.15 b c$ & $512.00 \pm 0.00 \mathrm{a}$ & $507.33 \pm 1.15 b$ & $504.00 \pm 2.00 \mathrm{c}$ & $506.67 \pm 2.31 \mathrm{bc}$ \\
\hline & $A_{\max }$ & $1.11 \pm 0.07 \mathrm{~b}$ & $2.18 \pm 0.04 \mathrm{a}$ & $1.13 \pm 0.06 \mathrm{~b}$ & $1.22 \pm 0.06 \mathrm{~b}$ & $1.12 \pm 0.05 b$ \\
\hline \multirow[t]{2}{*}{3} & $\lambda_{\max }$ & $500.00 \pm 3.00 \mathrm{~b}$ & $508.00 \pm 1.00 \mathrm{a}$ & $503.00 \pm 2.65 \mathrm{~b}$ & $500.00 \pm 0.00 \mathrm{~b}$ & $500.33 \pm 2.52 \mathrm{~b}$ \\
\hline & $\mathrm{A}_{\max }$ & $0.95 \pm 0.03 c$ & $1.98 \pm 0.07 \mathrm{a}$ & $1.07 \pm 0.06 \mathrm{~b}$ & $1.09 \pm 0.03 \mathrm{~b}$ & $1.17 \pm 0.06 \mathrm{~b}$ \\
\hline \multirow[t]{2}{*}{6} & $\lambda_{\max }$ & $501.67 \pm 1.53 \mathrm{bc}$ & $506.33 \pm 0.58 \mathrm{a}$ & $502.00 \pm 0.00 \mathrm{bc}$ & $502.33 \pm 2.08 b$ & $499.33 \pm 2.08 c$ \\
\hline & $\mathrm{A}_{\max }$ & $0.86 \pm 0.03 \mathrm{~d}$ & $1.81 \pm 0.02 \mathrm{a}$ & $1.02 \pm 0.01 \mathrm{bc}$ & $1.00 \pm 0.04 \mathrm{c}$ & $1.07 \pm 0.04 \mathrm{~b}$ \\
\hline \multirow[t]{2}{*}{12} & $\lambda_{\max }$ & $493.00 \pm 2 c$ & $505.67 \pm 0.58 \mathrm{a}$ & $500.67 \pm 2.89 \mathrm{~b}$ & $497.67 \pm 1.15 b$ & $499.67 \pm 3.21 b$ \\
\hline & $\mathrm{A}_{\max }$ & $0.83 \pm 0.02 c$ & $1.78 \pm 0.10 \mathrm{a}$ & $0.94 \pm 0.04 \mathrm{~b}$ & $0.95 \pm 0.02 \mathrm{~b}$ & $1.02 \pm 0.07 \mathrm{~b}$ \\
\hline
\end{tabular}

Note: $\lambda_{\max }$ : wavelength at maximum absorbance of cherry wine; $\mathrm{A}_{\max }$ : maximum absorbance of cherry wine. Different letters indicate that there is significant difference between different experimental groups at the same aging time $(p<0.05)$. These data are from the means of values \pm standard deviation.

The bathochromic shift of cherry wine was related to the formation of pyranoanthocyanin by the copigmentation effect [21]. The pyranoanthocyanin structure increased the chromophore, so it was accompanied by hyperchromic effect. Cherry wine underwent hypsochromic shift and hypochromic effect over time, which may be due to the inevitable degradation of anthocyanins and pyranoanthocyanin during aging.

Figure 2 shows the trend of copigmentation effect on M values, which first increased, then declined and gradually stabilized during aging. Wine samples with pigments reached the highest $M$ value after 3-6 months of aging. Among them, the M value of the BFSA group can reach $146 \%$ when aged for 3 months. The concentration of anthocyanins and copigment is an important factor affecting the copigmentation effect [20]. The total anthocyanin content of cherry juice before alcohol fermentation was $31.3 \mathrm{mg} / \mathrm{L}$, while after alcohol fermentation, it decreased to $5.1 \mathrm{mg} / \mathrm{L}$. Zhu et al. [36] investigated that the strongest immediate copigmentation effect at the 1:30 molar ratio occurred between the anthocyanins and sinapic acid. The excellent copigmentation effect of the BFSA group may be contributed by the molar ratio close to $1: 30$ when $300 \mathrm{mg} / \mathrm{L}$ sinapic acid was added before fermentation. Meanwhile, unlike the pyranoanthocyanins derived from coumaric acid and ferulic acid, 10-syringyl-pyranocyanidin-3-rutinoside (derived from sinapic acid) cannot be produced by enzymatic reaction but can be directly produced [37,38]. A large number of anthocyanin monomers were retained before alcohol fermentation, which is conducive to the production of pyranoanthocyanins. Therefore, sinapic acid added before fermentation is more efficient than that added after fermentation.

\subsection{Evaluation of the Color Effect of Copigments on Anthocyanins in Cherry Wine}

As shown in Figure 3, with the extension of the aging time, the color intensity of the control group decreased and the hue increased, indicating that the color became lighter. The copigmentation effect of sinapic acid, grape tannin and anthocyanin in cherry wine had a positive effect on the color of cherry wine. The copigmentation resulted in a significant increase of color intensity and decreased the hue, indicating a more vivid color characteristics [39]. In the aging stage, the BFSA group maintained a high color intensity, which was related to the hyperchromic effect. The BFGT group showed high color intensity at the beginning of aging. However, due to poor stability, the color intensity decreased with aging, while the AFGT group showed significantly higher color intensity than the control group in the later stage of aging. 


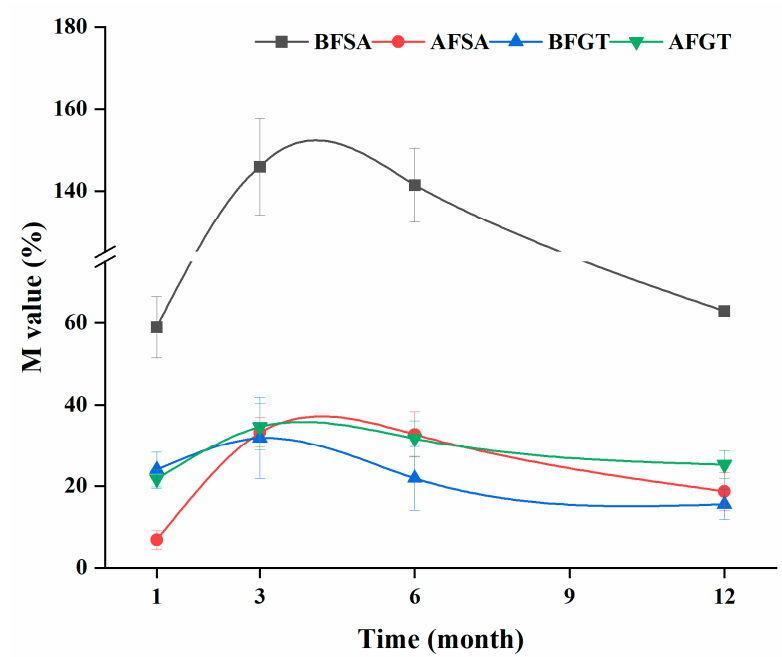

Figure 2. Effects of added sinapic acid and grape tannin on copigmentation effect value (M) of cherry wine.

A

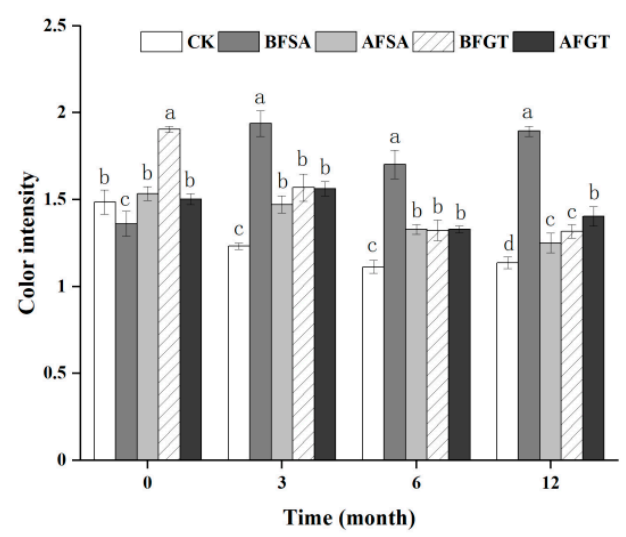

B

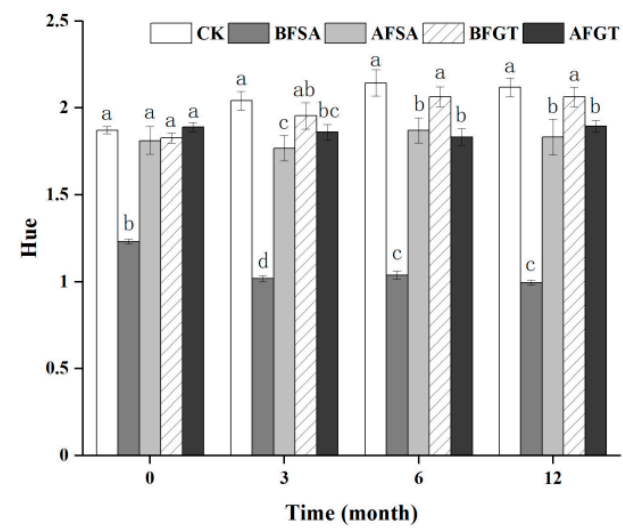

Figure 3. Effects of added sinapic acid and grape tannin on the color intensity $(\mathbf{A})$ and hue $(\mathbf{B})$ of cherry wine. Samples with different letters are significantly different $(p<0.05)$.

In the aging stage, $\mathrm{L}^{*}$ of the control group showed an upward trend, while $\mathrm{a}^{*}$ and $\mathrm{b}^{*}$ showed a downward trend (Figure 4). Compared with the control group, the copigmenttreated group showed lower $L^{*}$ values and higher $a{ }^{*}$ and $b{ }^{*}$ values in the CIELAB system, indicating a more pleasurable color characteristic. The lower $\mathrm{L}^{*}$ value involves darkness, which may be due to the hyperpigmentation effect caused by copigmentation [24]. Throughout the aging stage, the BFSA group always maintained significantly lower L* values and higher $\mathrm{a}^{*}$ values, which were consistent with higher anthocyanin content [36] and presented as a more red-orange color.

\subsection{Changes in Anthocyanins and Anthocyanin-Derived Compound in the Cherry Wines}

A total of eight anthocyanins were identified by UPLC-Q/TOF-MS, including two monomer forms and six pyranoanthocyanins. The pyranoanthocyanins are divided into two types of vitisins and four types of hydroxyphenyl pyranoanthocyanins. Table 2 lists the detailed information of anthocyanins and anthocyanin derivatives. The UPLC chromatograms and the mass spectra are shown in Figure 5 and Figure S1, respectively. A total of six anthocyanins were detected in the CK, BFGT and AFGT wine samples, seven anthocyanins were detected in the AFSA groups and eight anthocyanins were detected in the BFSA groups. 


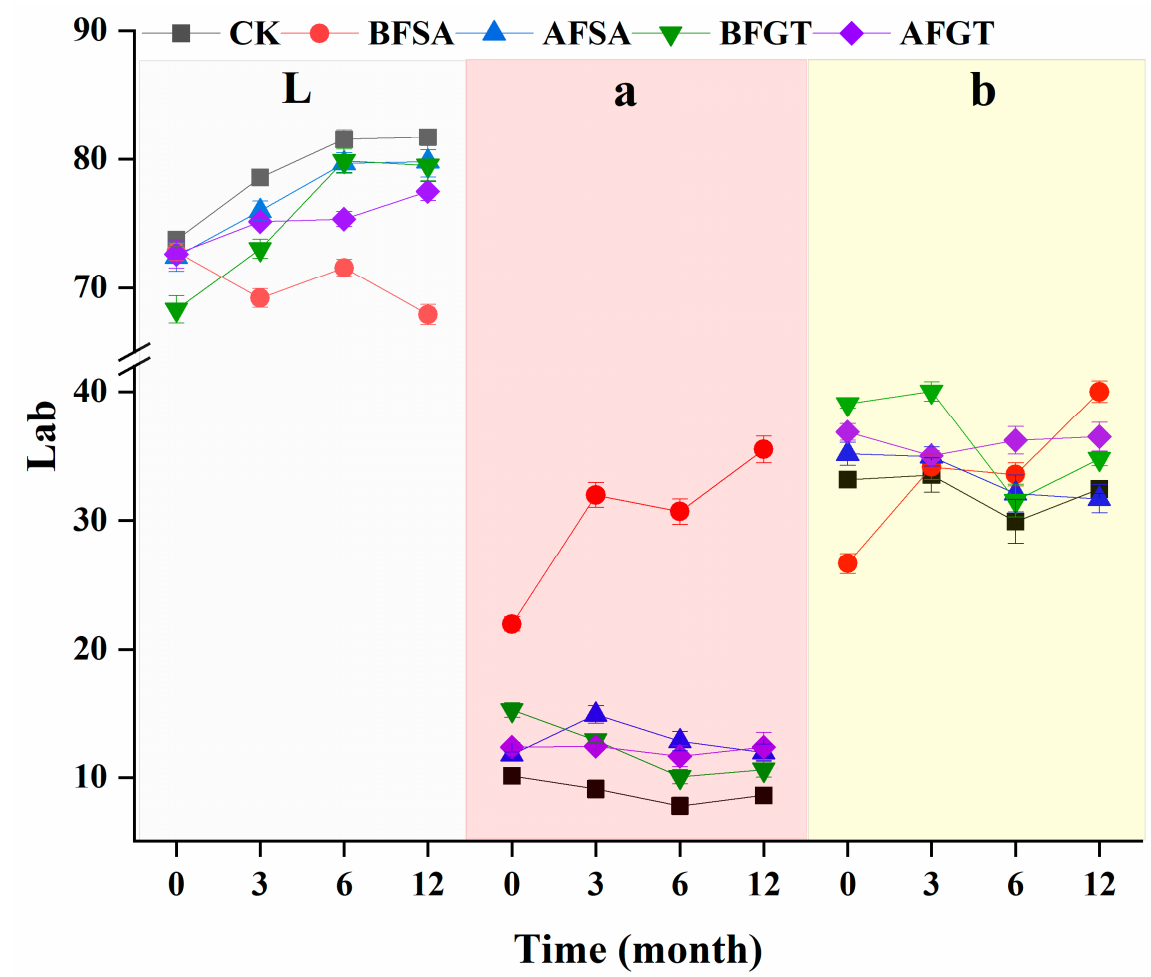

Figure 4. Effects of added sinapic acid and grape tannin on the color parameters brightness $\left(\mathrm{L}^{*}\right)$, redness $\left(a^{*}\right)$ and yellowness $\left(b^{*}\right)$ of cherry wine.

Table 2. Anthocyanins and anthocyanin-derived compounds identified in the cherry wines by UPLC-MS.

\begin{tabular}{|c|c|c|c|c|c|}
\hline Peak No. & Compound & $\begin{array}{c}\text { RT } \\
(\mathrm{min})\end{array}$ & $\begin{array}{c}{[\mathbf{M} . \mathbf{H}]^{+}} \\
(m / z)\end{array}$ & $\begin{array}{l}\text { Fragment } \\
(\mathrm{m} / \mathrm{z})\end{array}$ & $\lambda_{\text {vis-max }}$ \\
\hline 1 & Cyanidin-3-O-rutinoside & 10.7 & 595 & 287 & $519 \pm 0$ \\
\hline 2 & $\begin{array}{c}\text { 10-Carboxy-pyranocyanidin-3-O-rutinoside } \\
\text { (vitisin A type) }\end{array}$ & 11.0 & 663 & 355 & $512 \pm 0$ \\
\hline 3 & $\begin{array}{c}\text { 10H-Pyranocyanidin-3-O-rutinoside (vitisin B } \\
\text { type) }\end{array}$ & 11.8 & 619 & 311 & nd \\
\hline 4 & Peonidin-3-O-rutinoside & 12.2 & 609 & 301 & $519.67 \pm 0.58$ \\
\hline 5 & 10-Catechyl-pyranocyanidin-3-O-rutinoside & 15.1 & 727 & 419 & $506.67 \pm 0.94$ \\
\hline 6 & $\begin{array}{l}\text { 10-Hydroxyphenyl-pyranocyanidin-3-O- } \\
\text { rutinoside }\end{array}$ & 15.7 & 711 & 403 & $503.33 \pm 1.15$ \\
\hline 7 & 10-Guaiacyl-pyranocyanidin-3-O-rutinoside & 16.0 & 741 & 433 & $509.67 \pm 0.58$ \\
\hline 8 & 10-Syringyl-pyranocyanidin-3-rutinoside & 16.2 & 771 & 463 & $514 \pm 0$ \\
\hline
\end{tabular}

Note: $\lambda_{\text {vis-max }}$ : The maximum absorption wavelength of anthocyanins in red absorption region, data are from the means of values \pm standard deviation.

Cyanidin-3-O-rutinoside (cy-3-rut) was the main anthocyanin in fresh cherry wine, accounting for $76-85 \%$ of the total anthocyanin. Peonidin-3-O-rutinoside (pe-3-rut) accounted for about $9-18 \%$ after alcohol fermentation. Previously, the average concentration of pe-3-rut in cherry wine was about $1.31 \mathrm{mg} / \mathrm{L}$ [40], which was consistent with our results. The pyranoanthocyanins in cherry wine are derived from cy-3-rut, and the formation process is shown in Figure 6. It can be seen from Figure 7 that with the extension of aging time, the content of natural anthocyanins gradually decreased, while the content of pyranoanthocyanins gradually increased. 

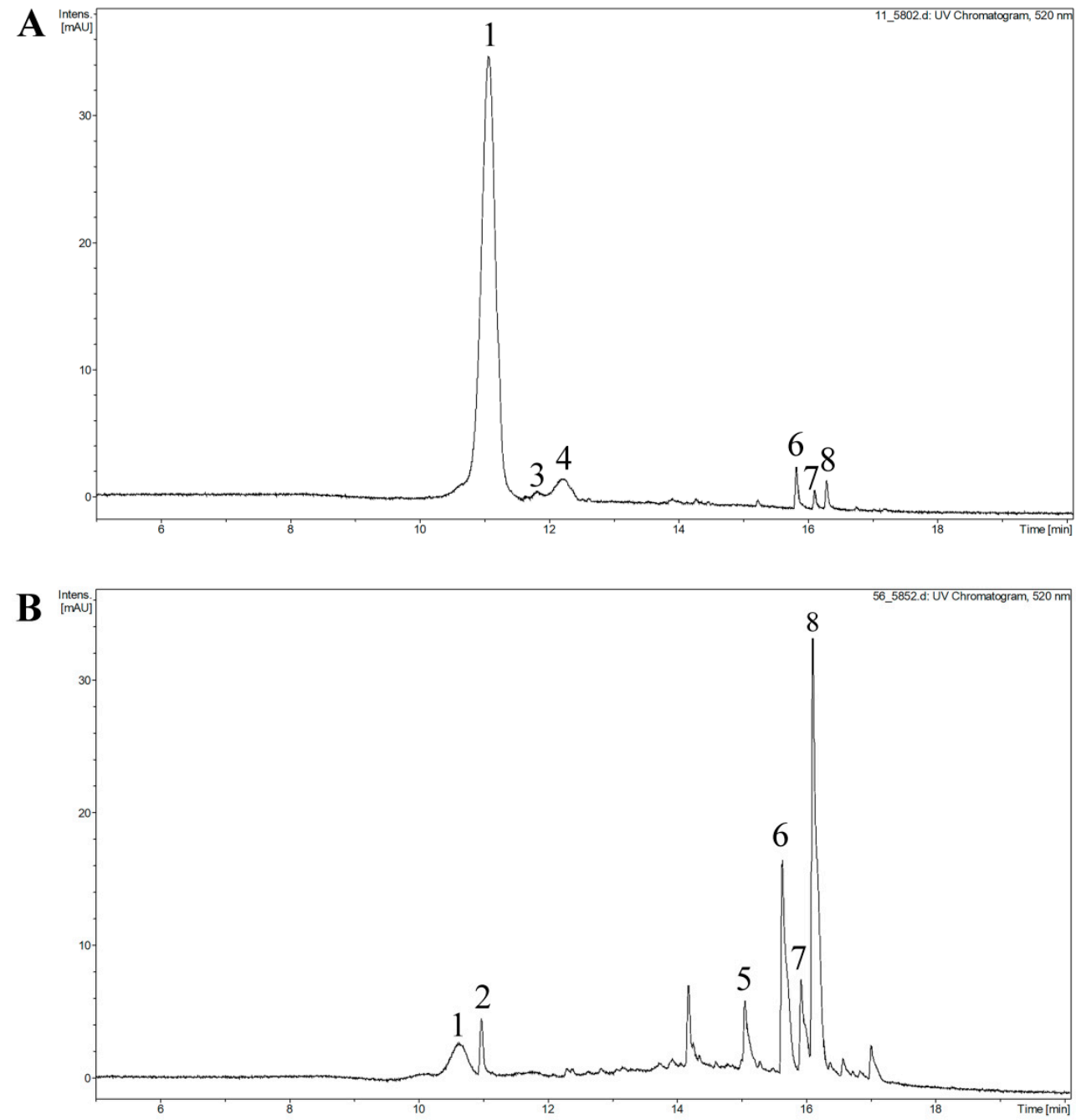

Figure 5. The UPLC chromatograms of BFSA group cherry wine in $520 \mathrm{~nm}$ (eight anthocyanins were detected in BFSA group), aging for 0 days (A); aging for one year (B). Peak 1, cyanidin3-rutinoside; peak 2, 10-carboxy-pyranocyanidin-3-O-rutinoside; peak 3, $10 \mathrm{H}$-pyranocyanidin-3$O$-rutinoside; peak 4, peonidin-3-rutinoside; peak 5, 10-catechypyranocyanidin-3-O-rutinoside; peak 6, 10-hydroxyphenyl-pyranocyanidin-3-O-rutinoside; peak 7, 10-guaiacyl-pyranocyanidin3-O-rutinoside; peak 8, 10-syringyl-pyranocyanidin-3-rutinoside.<smiles>[R1]COc1c(-c2ccc(O)c(O)c2)[o+]c2cc(O)cc3c2c1C=C([R])O3</smiles>

vitisin-like pyranoanthocyanins

acetaldehyde $\mathrm{R}_{1}=\mathrm{H} \quad 10 \mathrm{H}-$ pycy-3-rut pyruvic acid $\mathrm{R}_{1}=\mathrm{COOH} 10$-carboxy-pycy-3-rut

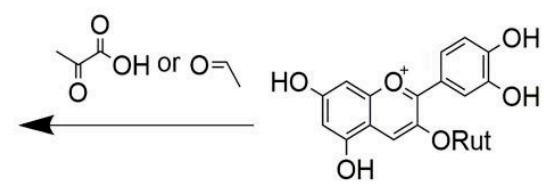

cyanidin-3-rutinoside

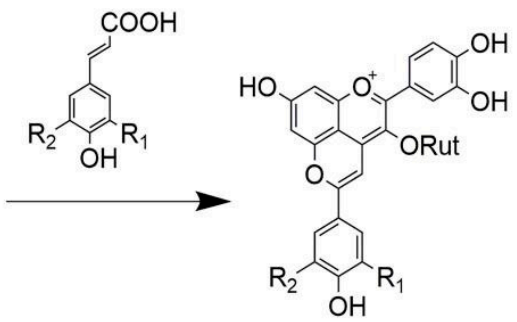

hydroxyphenyl-type pyranoanthocyanins

coumaric acid $\mathrm{R}_{1}=\mathrm{H} \mathrm{R}_{2}=\mathrm{H}$ 10-hydroxyphenyl-pycy-3-rut caffeic acid $\mathrm{R}_{1}=\mathrm{OH} \quad \mathrm{R}_{2}=\mathrm{H} \quad 10$-catechyl-pycy-3-rut ferulic acid $\mathrm{R}_{1}=\mathrm{OCH}_{3} \mathrm{R}_{2}=\mathrm{H}$ 10-guaiacyl-pycy-3-rut sinapic acid $\mathrm{R}_{1}=\mathrm{OCH}_{3} \mathrm{R}_{2}=\mathrm{OCH}_{3}$ 10-syringyl-pycy-3-rut

Figure 6. Pathway of formation of pyranoanthocyanins (abbreviations: $\mathrm{py}=$ pyrano, $\mathrm{cy}=$ cyanidin, rut $=3$-O-rutinoside). 

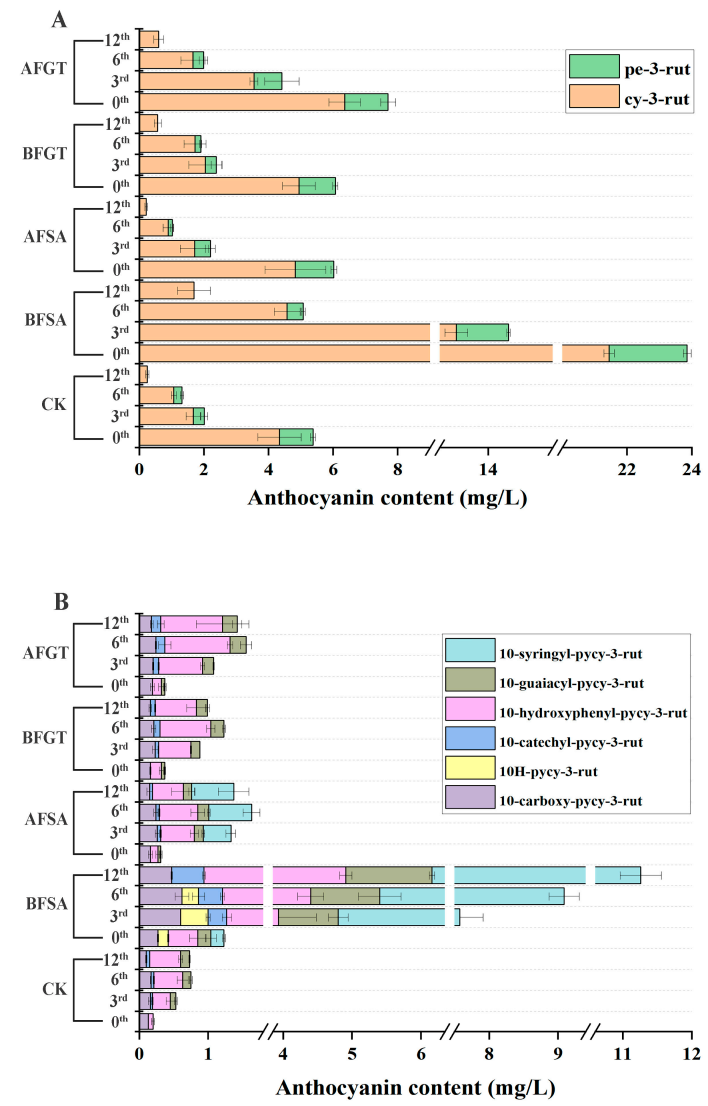

Figure 7. Effects of added sinapic acid and grape tannin on the content of natural anthocyanins (A) and pyranoanthocyanins (B) during one year aging (py: pyrano; cy: cyanidin; pe: peonidin; rut: 3-O-rutinoside; 0 th, 3rd, 6th and 12th: the 0th, 3rd, 6th and 12th months of aging, respectively).

10-Carboxy-pyranocyanidin-3-O-rutinoside (10-carboxy-pycy-3-rut) and 10H-pyranocyanidin3-O-rutinoside (10H-pycy-3-rut) were formed by reaction of cy-3-rut and yeast metabolites (pyruvic acid and acetaldehyde, respectively). After aging for 6 months, the content of 10-carboxy-pycy-3-rut in the copigment-treated cherry wine was significantly higher than that in control group $(p<0.05)$ and began to decrease slowly during the aging process of 6 to 12 months. This is consistent with the change trend of the pigment in bilberry wine [41]. $10 \mathrm{H}$-Pycy-3-rut only appeared in the BFSA group and was not detected at the end of aging. The reason may be that $10 \mathrm{H}$-pycy-3-rut slowly undergoes a hydration reaction, thus causing degradation $[17,42]$.

Peaks 5-8 are four types of hydroxyphenyl pyranoanthocyanins, which were formed by the reaction of cy-3-rut and hydroxycinnamic acid (caffeic acid, coumaric acid, ferulic acid and sinapic acid, respectively) or its decarboxylation products. 10-Catechylpyranocyanidin-3-O-rutinoside (10-catechyl-pycy-3-rut) was detected after 3 months of aging, 10-hydroxyphenyl-pyranocyanidin-3-O-rutinoside (10-hydroxyphenyl-pycy-3-rut) and 10-guaiacyl-pyranocyanidin-3-O-rutinoside (10-guaiacyl-pycy-3-rut) could be detected at the beginning of aging. This maybe because pyranoanthocyanins derived from coumaric acid and ferulic acid can not only be formed through cinnamate decarboxylase reactions in the fermentation process but can also be directly formed during aging [38]. The content of pyranoanthocyanins in cherry wine was increased by copigment treatments, in particular, 10-syringyl-pyranocyanidin-3-rutinoside (10-syringyl-pycy-3-rut) only appeared in cherry wine with sinapic acid. Therefore, during the whole aging process, the pyranoanthocyanin content of the BFSA group was significantly higher than that of other groups, followed by the AFSA group and AFGT group. Moreover, it can be seen from Figure 7 that the content of 10-syringol-pycy-3-rut in the BFSA group reached eight times than that of the AFSA group after aging for one year. Three important factors are required for the formation of 
pyranoanthocyanins [15]. As pyranoanthocyanins are reaction products of anthocyanins, cyanidin-3-rutinoside is necessary for their formation. The second factor is the reaction partner of anthocyanins. Previous studies have demonstrated that hydroxycinnamic acid and yeast metabolites react with anthocyanins to form the corresponding pyranoanthocyanins [19]. The third is storage time. Cherry wine is rich in anthocyanins and possible reaction partners, the formation of pyranoanthocyanins may be formed with increasing storage time, although they may not be present in the initial product. Therefore, some of the most important pyranoanthocyanins found in cherry wine result from the reaction between the original anthocyanins and yeast metabolites released during fermentation, for example pyruvic acid and acetaldehyde. Other pyranoanthocyanins could be obtained by the reaction of anthocyanins with natural phenolic acid present in cherry wines, for example caffeic acid, coumaric acid and ferulic acid. Added copigments belong to phenolic substances, which can promote the extraction of more pigments from the cherry juice into cherry wine, increasing the content of anthocyanins and more phenolic substances [11], thereby, facilitating the conversion of anthocyanins into more stable pyranoanthocyanins.

In addition, color parameters $\left(\mathrm{A}_{\max }, \lambda_{\max }, \mathrm{CI}, \mathrm{H}\right)$ and anthocyanin content were used for principal component analysis (Figure 8). Based on the analysis results, PC1 represents the red factor (positive) and PC2 the yellow factor (negative). At the beginning of aging, the cherry wine samples were distributed on the upper side of PC2, and after 12 months, they were distributed on the lower side. What is special is that the BFSA group always shows a positive contribution rate to PC1. There are obvious groupings of cherry wines before and after aging, which shows that the cherry wine has changed to a certain extent after aging, mainly due to the decrease of monomer anthocyanins and the increase of pyranoanthocyanins in the cherry wine during the aging process.

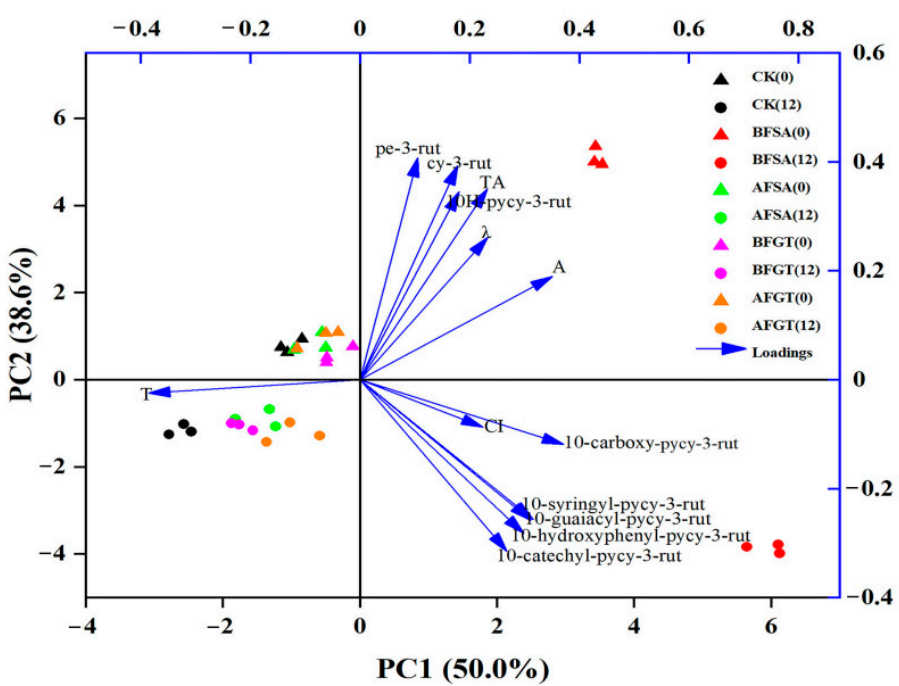

Figure 8. Principal component analysis for cherry wine during aging (0: aging for 0 months; 12 : aging for 12 months; arrow: the principal component load; $\lambda$ : wavelength at maximum absorbance of cherry wine; A: maximum absorbance of cherry wine; CI: color intensity; H: hue; TAs: total monomeric anthocyanins; py: pyrano; cy: cyanidin; pe: peonidin; rut: 3-O-rutinoside).

The results of MLR analysis (Table 3) showed that pe-3-rut content could explain 83\% of color intensity alone and hue was negatively correlated with 10-carboxy-pycy-3-rut and 10-syringyl-pycy-3-rut $(p<0.001)$ and positively correlated with 10-guaiacyl-pycy3-rut $(p<0.05)$. Furthermore, 10-carboxy-pycy-3-rut, pe-3-rut, 10-syringyl-pycy-3-rut and TAs were statistically positively correlated with $\mathrm{A}_{\max }$. Among them, $\mathrm{A}_{\max }$ had the strongest correlation with TAs $(p<0.001)$. The correlation coefficient was 0.678 . The pigment with the highest contribution to $\lambda_{\max }$ was 10-carboxy-pycy-3-rut $(p<0.05)$, with correlation coefficients of 0.728 . The components and content of anthocyanins had a positive contribution to the color intensity, bathochromic shift and hyperchromic effect of 
the cherry wine. Our research results indicate that sinapic acid and grape tannin can enrich the components of anthocyanins in cherry wine, so, during the aging process, sinapic acid and grape tannin can improve the color of cherry wine.

Table 3. Anthocyanins and anthocyanin-derived compounds identified in the cherry wines by UPLC-MS.

\begin{tabular}{|c|c|c|c|c|}
\hline Model & $R^{2}$ & DW & $\mathbf{F}$ & $P$ \\
\hline $\mathrm{CI}=1.397 \times$ pe-3-rut & 0.830 & 0.902 & 22.277 & $<0.001$ \\
\hline $\begin{array}{c}\mathrm{H}=-0.424 \times 10 \text {-carboxy-pycy-3-rut }+0.728 \times \\
\text { 10-guaiacyl-pycy-3-rut }-0.698 \times 10 \text {-syringyl-pycy-3-rut }\end{array}$ & 0.949 & 1.332 & 122.371 & $<0.001$ \\
\hline $\begin{aligned} \mathrm{A}_{\max }= & 0.201 \times 10 \text {-carboxy-pycy }+0.121 \times \text { pe-3-rut }+0.180 \\
& \times 10 \text {-syringyl-pycy-3-rut }+0.678 \times \mathrm{TA}\end{aligned}$ & 0.984 & 1.575 & 404.704 & $<0.001$ \\
\hline $\begin{aligned} \lambda_{\max }= & 0.728 \times 10 \text {-carboxy-pycy-3-rut }-0.528 \times \\
& 10 \mathrm{H} \text {-pycy-3-rut }+0.644 \times \text { pe-3-rut }\end{aligned}$ & 0.746 & 1.885 & 16.301 & $<0.001$ \\
\hline
\end{tabular}

Note: $\mathrm{R}^{2}$ : coefficient of determination; DW: test autocorrelation; $\mathrm{F}$ : variance test; $\mathrm{P}$ : judge whether the correlation is statistically significant; CI: color intensity; $\mathrm{H}$ : hue; $\lambda_{\max }$ : wavelength at maximum absorbance of cherry wine; $\mathrm{A}_{\max }$ : maximum absorbance of cherry wine; TAs: total monomeric anthocyanins; py: pyrano; cy: cyanidin; pe: peonidin; rut: 3-O-rutinoside.

\subsection{UV-Vis Spectra of Anthocyanins and Anthocyanin-Derived Compounds}

In the UPLC-MS analysis system, combined with a PDA detector, the UV-vis spectra of anthocyanins and newly formed pyranoanthocyanins were obtained. As shown in Table 2, compared with cy-3-rut, 10-carboxy-pycy-3-rut had a hypsochromic shift (7 nm) of maximum absorption wavelength in the red absorption region $\left(\lambda_{\text {vis-max }}\right)$. Moreover, the four hydroxyphenyl-type pyranoanthocyanins had a different level of hypsochromic shift. 10-Hydroxyphenyl-pycy-3-rut (one hydroxyl group) and 10-catechyl-pycy-3-rut (two hydroxyl groups) were at 503.3 and $506.7 \mathrm{~nm}$, respectively. 10-Guaiacyl-pycy-3-rut (one methoxy group) and 10-syringyl-pycy-3-rut (two methoxy groups) were at 509.7 and $514 \mathrm{~nm}$, respectively (Figure S2). The hydroxyl and methoxyl groups on the E ring have a positive effect on the stability of the pyranoanthocyanin [19], the higher the hydroxylation

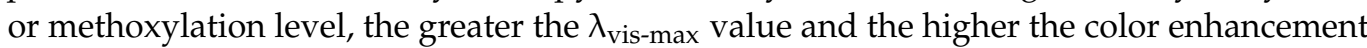
effect becomes [21]. Pyranoanthocyanins have a greater color expression than anthocyanins at the $\mathrm{pH}$ of wine [17], this also explains why the pyranoanthocyanin has a lower maximum absorption wavelength compared to the native anthocyanin but causes the cherry wine to have a bathochromic shift. In addition, anthocyanin is irreversibly degraded during storage, but the content of pyranoanthocyanin increases. This permits to profit from the total coloring capacity of the pyranoanthocyanins at the $\mathrm{pH}$ of cherry wine.

\section{Conclusions}

This research studied the changes of color and anthocyanin composition of cherry wine treated with copigments before and after fermentation during aging by spectral measurement combined with UPLC-MS quantitative analysis. The sinapic acid and grape tannin pretreatments of cherry wine exerted positive effects on the content of pyranoanthocyanins and wine color, producing wines with higher color intensity values (lower $\mathrm{L}^{*}$, higher $a^{*}$ and $b^{*}$ ) than the traditionally produced wines. Sinapic acid is suitable for adding before alcohol fermentation, while grape tannins can be added after alcohol fermentation. This study provides a strong evidence for the feasibility of the application of copigments in cherry wine.

Supplementary Materials: The following are available online, Figure S1: Mass spectra and fragmentation pattern of anthocyanins and anthocyanin-derived compounds in cherry wine. A-H correspond to peaks 1-8 in Figure 5 in turn. Figure S2: The chemical structure of cyanidin-3-rutinoside-derived pyranoanthocyanins in the cherry wine. Reaction products of cyanidin-3-rutinoside (1) with acetaldehyde (2), pyruvate (3), coumaric acid (4), caffeic acid (5), ferulic acid (6) and sinapic acid (7).

Author Contributions: Conceptualization, methodology, writing-original draft, M.L.; conceptualization, funding acquisition, supervision, writing-review and editing, X.Z.; resources, Y.S.; 
methodology, writing—original draft, Z.Y.; resources, writing—original draft, G.H.; conceptualization, writing - original draft, writing-review and editing, X.Y. All authors have read and agreed to the published version of the manuscript.

Funding: This research was supported by grants from the Modern Agricultural Technology System of Shandong Province [grant number SDAIT-06-14], the Natural Science Foundation of Shandong Province [grant number ZR2019BC114] and the National Natural Science Foundation of China [grant number 31701666].

Data Availability Statement: The data presented in this study are available in article and Supplementary Material.

Conflicts of Interest: The authors declare no conflict of interest.

Sample Availability: Samples of the compounds are not available from the authors.

\section{References}

1. Blando, F.; Oomah, B.D. Sweet and Sour Cherries: Origin, Distribution, Nutritional Composition and Health Benefits. Trends Food Sci. Technol. 2019, 86, 517-529. [CrossRef]

2. Ballistreri, G.; Continella, A.; Gentile, A.; Amenta, M.; Fabroni, S.; Rapisarda, P. Fruit Quality and Bioactive Compounds Relevant to Human Health of Sweet Cherry (Prunus avium L.) Cultivars Grown in Italy. Food Chem. 2013, 140, 630-638. [CrossRef] [PubMed]

3. Martini, S.; Conte, A.; Tagliazucchi, D. Phenolic Compounds Profile and Antioxidant Properties of Six Sweet Cherry (Prunus avium) Cultivars. Food Res. Int. 2017, 97, 15-26. [CrossRef] [PubMed]

4. Liu, Y.; Liu, X.; Zhong, F.; Tian, R.; Zhang, K.; Zhang, X.; Li, T. Comparative Study of Phenolic Compounds and Antioxidant Activity in Different Species of Cherries. J. Food Sci. 2011, 76, C633-C638. [CrossRef] [PubMed]

5. Čakar, U.; Petrović, A.; Pejin, B.; Čakar, M.; Živković, M.; Vajs, V.; Đorđević, B. Fruit as a Substrate for a Wine: A Case Study of Selected Berry and Drupe Fruit Wines. Sci. Hortic. 2019, 244, 42-49. [CrossRef]

6. Xiao, Z.; Fang, L.; Niu, Y.; Yu, H. Effect of Cultivar and Variety on Phenolic Compounds and Antioxidant Activity of Cherry Wine. Food Chem. 2015, 186, 69-73. [CrossRef] [PubMed]

7. He, F.; Liang, N.N.; Mu, L.; Pan, Q.H.; Wang, J.; Reeves, M.J.; Duan, C.Q. Anthocyanins and Their Variation in Red Wines I. Monomeric Anthocyanins and Their Color Expression. Molecules 2012, 17, 1571-1601. [CrossRef] [PubMed]

8. Pacheco-Palencia, L.A.; Talcott, S.T. Chemical Stability of Açai Fruit (Euterpe oleracea Mart.) Anthocyanins as Influenced by Naturally Occurring and Externally Added Polyphenolic Cofactors in Model Systems. Food Chem. 2010, 118, 17-25. [CrossRef]

9. Turturica, M.; Oancea, A.M.; Rapeanu, G.; Bahrim, G. Anthocyanins: Naturally Occuring Fruit Pigments with Functional Properties. Ann. Univ. Dunarea Jos Galati Fascicle VI Food Technol. 2015, 39, 9-24.

10. Malaj, N.; Simone, B.; Quartarolo, A.; Russo, N. Spectrophotometric Study of the Copigmentation of Malvidin 3-O-glucoside with p-coumaric, Vanillic and Syringic Acids. Food Chem. 2013, 141, 3614-3620. [CrossRef] [PubMed]

11. Escribano, T.; Santos-Buelga, C. Anthocyanin Copigmentation-Evaluation, Mechanisms and Implications for the Colour of Red Wines. Curr. Org. Chem. 2012, 16, 715-723.

12. Boulton, R. The Copigmentation of Anthocyanins and Its Role in the Color of Red Wine: A Critical Review. Am. J. Enol. Vitic 2001, 52, 67-87.

13. Blanco-Vega, D.; López-Bellido, F.; Alía-Robledo, J.; Hermosín-Gutiérrez, I. HPLC-DAD-ESI-MS/MS Characterization of Pyranoanthocyanins Pigments Formed in Model Wine. J. Agric. Food Chem. 2011, 59, 9523-9531. [CrossRef] [PubMed]

14. Blanco-Vega, D.; Gómez-Alonso, S.; Hermosín-Gutiérrez, I. Identification, Content and Distribution of Anthocyanins and Low Molecular Weight Anthocyanin-derived Pigments in Spanish Commercial Red Wines. Food Chem. 2014, 158, 449-458. [CrossRef]

15. Rentzsch, M.; Schwarz, M.; Winterhalter, P. Pyranoanthocyanins-an Overview on Structures, Occurrence, and Pathways of Formation. Trends Food Sci. Technol. 2007, 18, 526-534. [CrossRef]

16. Oliveira, J.; Fernandes, V.; Miranda, C.; Santos-Buelga, C.; Silva, A.; Freitas, V.; Mateus, N. Color Properties of Four Cyanidin-Pyruvic Acid Adducts. J. Agric. Food Chem. 2006, 54, 6894-6903. [CrossRef]

17. De Freitas, V.; Mateus, N. Formation of Pyranoanthocyanins in Red Wines: A New and Diverse Class of Anthocyanin Derivatives. Anal. Bioanal. Chem. 2011, 401, 1463-1473. [CrossRef]

18. Pina, F.; Oliveira, J.; de Freitas, V. Anthocyanins and Derivatives are More Than Flavylium Cations. Tetrahedron 2015, 71, 3107-3114. [CrossRef]

19. Sun, J.; Li, X.; Luo, H.; Ding, L.; Jiang, X.; Li, X.; Jiao, R.; Bai, W. Comparative Study on the Stability and Antioxidant Activity of Six Pyranoanthocyanins Based on Malvidin-3-glucoside. J. Agric. Food Chem. 2020, 68, 2783-2794. [CrossRef]

20. Heras-Roger, J.; Díaz, C.; Darias-Martín, J. What Gives a Wine Its Strong Red Color? Main Correlations Affecting Copigmentation. J. Agric. Food Chem. 2016, 64, 6567-6574. [CrossRef]

21. Yawadio, R.; Morita, N. Color Enhancing Effect of Carboxylic Acids on Anthocyanins. Food Chem. 2007, 105, 421-427. [CrossRef]

22. Ko, A.; Lee, J.S.; Nam, H.; Lee, H. Stabilization of Black Soybean Anthocyanin by Chitosan Nanoencapsulation and Copigmentation. J. Food Biochem. 2016, 41. [CrossRef] 
23. Neves, A.C.; Spranger, M.I.; Zhao, Y.; Leandro, M.C.; Sun, B. Effect of Addition of Commercial Grape Seed Tannins on Phenolic Composition, Chromatic Characteristics, and Antioxidant Activity of Red Wine. J. Agric. Food Chem. 2010, 58, 11775-11782. [CrossRef] [PubMed]

24. Liu, Y.X.; Liang, N.N.; Wang, J.; Pan, Q.H.; Duan, C.Q. Effect of the Prefermentative Addition of Five Enological Tannins on Anthocyanins and Color in Red Wines. J. Food Sci. 2013, 78, C25-C30. [CrossRef] [PubMed]

25. Vivas, N.; Nonier, M.F.; Gaulejac, N.; Absalon, C.; Bertrand, A.; Mirabel, M. Differentiation of Proanthocyanidin Tannins from Seeds, Skins and Stems of Grapes (Vitis vinifera) and Heartwood of Quebracho (Schinopsis balansae) by Matrix-assisted Laser Desorption/Ionization Time-of-flight Mass Spectrometry and Thioacidolysis/Liquid Chromatography/Electrospray Ionization Mass Spectrometry. Anal. Chim. Acta 2004, 513, 247-256.

26. Giusti, M.M.; Wrolstad, R.E. Characterization and Measurement of Anthocyanins by UV-Visible Spectroscopy. Curr. Protoc. Food Anal. Chem. 2001, 0, F1.2.1-F1.2.13. [CrossRef]

27. Boulton, R. A Method for the Assessment of Copigmentation in Red Wines. In Proceedings of the 47th Annual Meeting of the American Society for Enology and Viticulture, Reno, NV, USA, 26-28 June 1996.

28. Li, X.; Zhang, L.; Peng, Z.; Zhao, Y.; Wu, K.; Zhou, N.; Yan, Y.; Ramaswamy, H.S.; Sun, J.; Bai, W. The Impact of Ultrasonic Treatment on Blueberry Wine Anthocyanin Color and Its in vitro Anti-oxidant Capacity. Food Chem. 2020, 333, 127455. [CrossRef] [PubMed]

29. Han, F.L.; Zhang, W.N.; Pan, Q.H.; Zheng, C.R.; Chen, H.Y.; Duan, C.Q. Principal Component Regression Analysis of the Relation Between CIELAB Color and Monomeric Anthocyanins in Young Cabernet Sauvignon Wines. Molecules 2008, 13, $2859-2870$. [CrossRef] [PubMed]

30. Kanha, N.; Surawang, S.; Pitchakarn, P.; Regenstein, J.M.; Laokuldilok, T. Copigmentation of cyanidin 3-O-glucoside with Phenolics: Thermodynamic Data and Thermal Stability. Food Biosci. 2019, 30, 100419. [CrossRef]

31. Kalisz, S.; Oszmiański, J.; Hładyszowski, J.; Mitek, M. Stabilization of Anthocyanin and Skullcap Flavone ComplexesInvestigations with Computer Simulation and Experimental Methods. Food Chem. 2013, 138, 491-500. [CrossRef]

32. Sinela, A.; Rawat, N.; Mertz, C.; Achir, N.; Fulcrand, H.; Dornier, M. Anthocyanins Degradation during Storage of Hibiscus sabdariffa Extract and Evolution of Its Degradation Products. Food Chem. 2017, 214, 234-241. [CrossRef] [PubMed]

33. Jiang, T.; Mao, Y.; Sui, L.; Yang, N.; Li, S.; Zhu, Z.; Wang, C.; Yin, S.; He, J.; He, Y. Degradation of Anthocyanins and Polymeric Color Formation during Heat Treatment of Purple Sweet Potato Extract at Different pH. Food Chem. 2019, 274, 460-470. [CrossRef] [PubMed]

34. Ertan, K.; Türkyılmaz, M.; Özkan, M. Effects of Natural Copigment Sources in Combination with Sweeteners on the Stability of Anthocyanins in Sour Cherry Nectars. Food Chem. 2019, 294, 423-432. [CrossRef] [PubMed]

35. Ertan, K.; Türkyılmaz, M.; Özkan, M. Effect of Sweeteners on Anthocyanin Stability and Colour Properties of Sour Cherry and Strawberry Nectars during Storage. J. Food Sci. Technol. 2018, 55, 4346-4355. [CrossRef] [PubMed]

36. Zhu, Y.; Chen, H.; Lou, L.; Chen, Y.; Ye, X.; Chen, J. Copigmentation Effect of Three Phenolic Acids on Color and Thermal Stability of Chinese Bayberry Anthocyanins. Food Sci. Nutr. 2020, 8, 3234-3242. [CrossRef] [PubMed]

37. Chatonnet, P.; Dubourdieu, D.; Boidron, J.; Lavigne, V. Synthesis of Volatile Phenols by Saccharomyces cerivisae in Wines. J. Sci. Food Agric. 1993, 62, 191-202. [CrossRef]

38. Akdemir, H.; Silva, A.; Zha, J.; Zagorevski, D.V.; Koffas, M.A.G. Production of Pyranoanthocyanins Using Escherichia coli Co-cultures. Metab. Eng. 2019, 55, 290-298. [CrossRef]

39. Klisurova, D.; Petrova, I.; Ognyanov, M.; Georgiev, Y.; Denev, P. Co-pigmentation of Black Chokeberry (Aronia melanocarpa) Anthocyanins with Phenolic Co-pigments and Herbal Extracts. Food Chem. 2019, 279, 162-170. [CrossRef] [PubMed]

40. Czyżowska, A.; Pogorzelski, E. Changes to Polyphenols in the Process of Production of Must and Wines from Blackcurrants and Cherries. Part II. Anthocyanins and Flavanols. Eur. Food Res. Technol. 2004, 218, 355-359. [CrossRef]

41. Liu, S.; Laaksonen, O.; Yang, W.; Zhang, B.; Yang, B. Pyranoanthocyanins in Bilberry (Vaccinium myrtillus L.) Wines Fermented with Schizosaccharomyces Pombe and Their Evolution during Aging. Food Chem. 2020, 305. [CrossRef] [PubMed]

42. He, J.; Oliveira, J.; Silva, A.M.; Mateus, N.; De Freitas, V. Oxovitisins: A New Class of Neutral Pyranone-anthocyanin Derivatives in Red Wines. J. Agric. Food Chem. 2010, 58, 8814-8819. [CrossRef] [PubMed] 